\title{
Prospective multicenter assessment of perioperative and minimum 2-year postoperative complication rates associated with adult spinal deformity surgery
}

\author{
Justin S. Smith, MD, PhD, ${ }^{1}$ Eric Klineberg, MD, ${ }^{2}$ Virginie Lafage, $\mathrm{PhD},{ }^{3}$ \\ Christopher I. Shaffrey, MD, ${ }^{1}$ Frank Schwab, MD, ${ }^{3}$ Renaud Lafage, MS, ${ }^{3}$ \\ Richard Hostin, MD, ${ }^{4}$ Gregory M. Mundis Jr., MD, ${ }^{5}$ Thomas J. Errico, MD, ${ }^{3}$ Han Jo Kim, MD, ${ }^{5}$ \\ Themistocles S. Protopsaltis, MD, ${ }^{3}$ D. Kojo Hamilton, MD, ${ }^{6}$ Justin K. Scheer, BS, ${ }^{7}$ \\ Alex Soroceanu, MD, ${ }^{8}$ Michael P. Kelly, MD, ${ }^{9}$ Breton Line, BSME, ${ }^{10}$ Munish Gupta, MD, ${ }^{2}$ \\ Vedat Deviren, MD, ${ }^{11}$ Robert Hart, MD, ${ }^{12}$ Douglas C. Burton, MD, ${ }^{13}$ Shay Bess, MD, ${ }^{10}$ \\ Christopher P. Ames, MD, ${ }^{14}$ and the International Spine Study Group
}

${ }^{1}$ Department of Neurosurgery, University of Virginia Health System, Charlottesville, Virginia; '2Department of Orthopaedic Surgery, University of California, Davis, Sacramento, California; ${ }^{3}$ Department of Orthopaedic Surgery, NYU Hospital for Joint Diseases, and ${ }^{5}$ Department of Orthopaedic Surgery, Hospital for Special Surgery, New York, New York; ${ }^{4}$ Department of Orthopaedic Surgery, Baylor Scoliosis Center, Plano, Texas; ${ }^{5}$ San Diego Spine Foundation, La Jolla, California; ${ }^{6}$ Department of Neurosurgery, University of Pittsburgh Medical Center, Pittsburgh, Pennsylvania; ${ }^{7}$ University of California San Diego School of Medicine, San Diego, California; ${ }^{8}$ Department of Orthopaedic Surgery, University of Calgary, Alberta, Canada; ${ }^{9}$ Department of Orthopedic Surgery, Washington University, St. Louis, Missouri; ${ }^{10}$ Department of Orthopedic Surgery, Rocky Mountain Hospital for Children, Denver, Colorado; Departments of ${ }^{11}$ Orthopedic Surgery and ${ }^{14}$ Neurosurgery, University of California, San Francisco, California; ${ }^{2}$ Department of Orthopaedic Surgery, Oregon Health \& Science University, Portland, Oregon; and ${ }^{13}$ Department of Orthopedic Surgery, University of Kansas Medical Center, Kansas City, Kansas

OBJECTIVE Although multiple reports have documented significant benefit from surgical treatment of adult spinal deformity (ASD), these procedures can have high complication rates. Previously reported complications rates associated with ASD surgery are limited by retrospective design, single-surgeon or single-center cohorts, lack of rigorous data on complications, and/or limited follow-up. Accurate definition of complications associated with ASD surgery is important and may serve as a resource for patient counseling and efforts to improve the safety of patient care. The authors conducted a study to prospectively assess the rates of complications associated with ASD surgery with a minimum 2-year follow-up based on a multicenter study design that incorporated standardized data-collection forms, on-site study coordinators, and regular auditing of data to help ensure complete and accurate reporting of complications. In addition, they report age stratification of complication rates and provide a general assessment of factors that may be associated with the occurrence of complications.

METHODS As part of a prospective, multicenter ASD database, standardized forms were used to collect data on surgery-related complications. On-site coordinators and central auditing helped ensure complete capture of complication data. Inclusion criteria were age older than 18 years, ASD, and plan for operative treatment. Complications were classified as perioperative (within 6 weeks of surgery) or delayed (between 6 weeks after surgery and time of last follow-up), and as minor or major. The primary focus for analyses was on patients who reached a minimum follow-up of 2 years.

RESULTS Of 346 patients who met the inclusion criteria, 291 (84\%) had a minimum 2-year follow-up (mean 2.1 years); their mean age was 56.2 years. The vast majority (99\%) had treatment including a posterior procedure, $25 \%$ had an anterior procedure, and $19 \%$ had a 3 -column osteotomy. At least 1 revision was required in 82 patients (28.2\%). A total of 270 perioperative complications ( 145 minor; 125 major) were reported, with 152 patients $(52.2 \%)$ affected, and a total of 199 delayed complications (62 minor; 137 major) were reported, with 124 patients (42.6\%) affected. Overall, 469 com-

ABBREVIATIONS ASA = American Society of Anesthesiologists; $\mathrm{ASD}=$ adult spinal deformity; $\mathrm{BMI}=$ body mass index; $\mathrm{CCl}=\mathrm{Charlson}$ Comorbidity Index; $\mathrm{EBL}=$ estimated blood loss; $\mathrm{HRQOL}=$ health-related quality of life; $\mathrm{LL}=$ lumbar lordosis; $\mathrm{PCS}$ = Physical Component Summary; $\mathrm{PI}=$ pelvic incidence; PI-LL = mismatch between pelvic incidence and lumbar lordosis; PJK = proximal junctional kyphosis; PT = pelvic tilt; SRS = Scoliosis Research Society; SVA = sagittal vertical axis.

SUBMITTED August 29, 2015. ACCEPTED November 3, 2015.

INCLUDE WHEN CITING Published online February 26, 2016; DOI: 10.3171/2015.11.SPINE151036. 
plications (207 minor; 262 major) were documented, with 203 patients (69.8\%) affected. The most common complication categories included implant related, radiographic, neurological, operative, cardiopulmonary, and infection. Higher complication rates were associated with older age $(p=0.009)$, greater body mass index $(p \leq 0.031)$, increased comorbidities ( $p$ $\leq 0.007$ ), previous spine fusion $(p=0.029)$, and 3 -column osteotomies $(p=0.036)$. Cases in which 2-year follow-up was not achieved included 2 perioperative mortalities (pulmonary embolus and inferior vena cava injury).

CONCLUSIONS This study provides an assessment of complications associated with ASD surgery based on a prospective, multicenter design and with a minimum 2-year follow-up. Although the overall complication rates were high, in interpreting these findings, it is important to recognize that not all complications are equally impactful. This study represents one of the most complete and detailed reports of perioperative and delayed complications associated with ASD surgery to date. These findings may prove useful for treatment planning, patient counseling, benchmarking of complication rates, and efforts to improve the safety and cost-effectiveness of patient care.

http://thejns.org/doi/abs/10.3171/2015.11.SPINE151036

KEY WORDS adult spinal deformity; complications; prospective; scoliosis; surgery

I $\mathrm{T}$ is well recognized that many developed countries, including the United States, are experiencing an unprecedented demographic shift toward an older population. As the ranks of the elderly grow, it will be increasingly important to appreciate and address their health care needs. Although the prevalence of adult spinal deformity (ASD) has been estimated to range from $2 \%$ to $32 \%$ in the general population, $7,10,21,35,38$ its prevalence has been estimated to be as high as $68 \%$ among the elderly. ${ }^{41}$ The finding of spinal deformity in many adults may be simply incidental and require only education and follow-up, but for many others, the condition may result in substantial pain and disability. ${ }^{1,11,13,47}$

Bess et al. recently underscored the health impact of ASD relative to normative and chronic disease values of the SF-36 Physical Component Summary (PCS score) in the United States. ${ }^{3}$ They noted that the PCS values for the symptomatic ASD patients in their series were similar to values reported by patients with other chronic conditions, including diabetes, heart disease, and rheumatoid arthritis. In addition, patients with more severe forms of ASD demonstrated worse PCS values than those reported by patients with limited use of their arms and legs. Pellisé et al. have also recently assessed the impact of ASD on health-related quality of life (HRQOL) compared with other conditions, including arthritis, chronic lung disease, diabetes, and congestive heart failure. ${ }^{34}$ They reported that surgical candidates with ASD had the worst HRQOL scores among the chronic conditions they assessed.

Although nonoperative treatments are often the firstline approach for symptomatic ASD, surgical treatment may be an option for patients who have unsatisfactory improvement. Multiple recent reports have demonstrated the potential of surgical treatment of ASD to provide significant improvement in pain, disability, and HRQOL. 5,6,25, 48,49,53-57,60 However, these procedures are often complex and may be associated with high rates of complications. ${ }^{4,6}$, 14,15,17,22,39,44,45,50-52,55,58,61,63 Previously reported studies of ASD surgery complications have been limited by retrospective design, single-surgeon or single-center cohorts, lack of rigorous data on complications, and/or limited follow-up. Improved understanding of the types of complications and their rates of occurrence with ASD surgery, both during the perioperative period and over the course of follow-up, is important for treatment planning, patient counseling, and ongoing efforts to improve the safety of care. In addition, more accurate documentation of the complications and rates of complications associated with ASD surgery is an important basis for future studies to define which complications may have impact on patient recovery or outcomes and to define the potential economic impact of specific complications from societal and payer perspectives. ${ }^{18,29,33}$

Our objectives in the present study were to prospectively assess the rates of complications associated with ASD surgery with minimum 2-year follow-up based on a multicenter study design that incorporated standardized data-collection forms, on-site study coordinators, and regular auditing of data to help ensure complete and accurate reporting of complications. In addition, the present study provides age stratification of complication rates and provides a general assessment of factors that may be associated with the occurrence of complications.

\section{Methods}

\section{Patient Population}

Patients were enrolled into a database through an institutional review board-approved protocol at 11 sites across the United States. Database inclusion criteria were age older than 18 years and at least 1 of the following radiographic measures: scoliosis of $20^{\circ}$ or more, sagittal vertical axis (SVA) of $5 \mathrm{~cm}$ or longer, pelvic tilt (PT) of $25^{\circ}$ or more, and thoracic kyphosis of $60^{\circ}$ or more. At the time of study enrollment, patients were classified into either operative or nonoperative treatment groups based on the initial management approach. For patients undergoing operative treatment, the procedural choice and instrumentation used, as well as the extent of surgery and operative objectives, were at the discretion of the operating surgeon. One of our a priori objectives in establishing this database was to review early and late complications among age groups, deformities, and surgical procedures. The present study focuses on operatively treated patients with a minimum 2-year follow-up after surgical treatment and is a multicenter, prospective assessment of consecutive ASD patients. Patients analyzed in the present study were those enrolled over the 4-year interval of August 2008 through August 2012.

A summary of complications for patients who were 
eligible for, but did not achieve, 2-year follow-up is provided as a means of assessing confounding effects on reported types and rates of complications that may be introduced by patients lost to follow-up. Both early and delayed complications for the patients lost to follow-up are presented separately and are not included in the complications for the patient group that achieved a minimum 2-year follow-up.

\section{Data Collection and Radiographic Assessment}

Standardized data-collection forms were used to collect patient demographics, imaging studies, patients' comorbidities, and details of surgical procedures and complications. De-identified data collected from each site were sent to a single center where all the data sets were summarized and analyzed, and the complications reviewed. Complications were classified as perioperative or delayed, and as minor or major. Perioperative complications were those occurring within 6 weeks of surgery, and delayed complications were those occurring between 6 weeks after surgery and the time of last follow-up. A complication was classified as major if it substantially prolonged hospitalization, involved an invasive intervention, had prolonged or permanent morbidity, or resulted in death. For example, implant prominence or a painful implant that did not require revision was classified as minor, whereas a revision procedure was classified as major. Any complication associated with the need for reoperation was considered major. Perioperative complications that occurred with reoperations were also included in the present study. Cases of rod fracture were classified as major, regardless of whether the patient had undergone revision for the rod fracture at the time of data extraction. Although a small subset of rod fractures may follow a relatively benign course, our experience has been that the distinct majority ultimately need a revision procedure. Although it could be argued to attempt to split these into minor versus major, given that CT imaging was not available for all cases to more clearly assess fusion status, it was decided to err on the side of upgrading these to the major category.

For the complication category "anemia/excessive blood loss," we classified patients having an estimated blood loss (EBL) greater than $4 \mathrm{~L}$ as a major complication, and classified patients reported to have an acute blood-loss anemia in the setting of an EBL that did not exceed $4 \mathrm{~L}$ as having a minor complication.

Although there remains controversy regarding whether some adverse events should be considered true complications (e.g., CSF leak in the setting of revision surgery or proximal junctional kyphosis [PJK] in the absence of clinical symptoms), we chose to err on the side of inclusion.

Full-length, free-standing anteroposterior and lateral spine radiographs were obtained at the following specified time intervals: preoperative, 6 weeks postoperatively (a window of 1-7 weeks), 1 year postoperatively (a window of 10-14 months), and 2-years postoperative (24-30 months). Radiographs were analyzed using validated software (Spineview; ENSAM Laboratory of Biomechanics). ${ }^{8,37}$ All radiographic measures were performed at a central location, based on standard techniques ${ }^{2,32}$ including scoliosis, lumbar lordosis (LL; Cobb angle between superior endplate of L-1 and superior endplate of S-1), sagittal vertical axis (SVA), pelvic tilt (PT), pelvic incidence (PI), and mismatch between PI and LL (PI-LL), as previously described. ${ }^{2,32}$ Patients were classified based on the Scoliosis Research Society (SRS)-Schwab adult thoracolumbar spinal deformity classification. ${ }^{42,48}$

\section{Data and Statistical Analysis}

Frequency distributions and summary statistics were calculated for all variables. The data were assessed using the Kolmogorov-Smirnov test for normality. For categorical variables, cross-tabulations were generated and Fisher's exact or Pearson chi-square tests were used to compare distributions. For continuous variables with normal distribution, statistical comparisons were performed using Student t-tests and ANOVA tests. For data that were not normally distributed, the Kruskal-Wallis test was used to determine statistical associations. Statistical analyses were 2 sided, and $p<0.05$ was considered statistically significant.

\section{Results \\ Patient Population}

Of 346 patients who met inclusion criteria, 291 (84\%) achieved a minimum 2-year follow-up (mean 2.1 years) and these patients were the primary focus of subsequent analyses. Demographic and operative parameters for these 291 patients are summarized in Table 1 . The mean age was 56.2 years (SD 15.2 years), and the distribution of patients by age group was as follows: $18-44$ years, $19.2 \%$; 45-64 years, 48.1\%; and 65-86 years, 32.6\%. Older patients had greater body mass index (BMI; $\mathrm{p}<0.001)$, higher Charlson Comorbidity Index (CCI; p < 0.001), higher American Society of Anesthesiologists (ASA; $p<0.001)$ score, higher incidence of previous spine surgery $(\mathrm{p}<0.001)$, and lower incidence of current smoking $(\mathrm{p}=0.001)$ (Table 1). Almost all patients (99\%) underwent a posterior procedure, with a mean of $11.1(\mathrm{SD}=4.5)$ operated vertebral levels. An anterior procedure was performed in $25.4 \%$ of patients, with a mean of 3.1 (SD 1.3) operated vertebral levels. Osteotomies were performed in the majority of patients $(64.3 \%)$, and older patients had a trend toward greater need for pedicle subtraction osteotomy $(\mathrm{p}=0.053)$ (Table 1). Older patients were also more likely to require a decompression $(\mathrm{p}<0.001)$ and had greater operative time $(\mathrm{p}<0.001)$, EBL $(\mathrm{p}=0.006)$, and hospital length of stay ( $\mathrm{p}$ $=0.001)($ Table 1$)$.

Figure 1 summarizes the distribution of deformities based on the SRS-Schwab Adult Spinal Deformity Classification. Coronal curve classifications were similarly distributed across the $\mathrm{L}, \mathrm{D}$, and $\mathrm{N}$ types, with a lesser representation of the T type. Abnormal PT, SVA, and PI-LL modifiers were present in $63 \%, 55 \%$, and $56 \%$ of patients, respectively.

For the 55 patients who did not reach the minimum 2-year follow-up, the mean follow-up duration was 0.57 years, with 7 patients having no follow-up available following discharge, 19 patients having no follow-up beyond 6 weeks, and 29 patients having no follow-up beyond 1 year. These patients did not differ significantly those who reached the 2-year follow-up mark with regard to baseline demographic and operative parameters. Patients with and 
TABLE 1. Demographic and operative parameters for 291 patients surgically treated for ASD stratified by age group*

\begin{tabular}{|c|c|c|c|c|c|}
\hline \multirow[b]{2}{*}{ Parameter } & \multicolumn{4}{|c|}{ Patient Age Group } & \multirow[b]{2}{*}{ All Patients } \\
\hline & $18-44$ Yrs & $45-64$ Yrs & $65-86$ Yrs & p Value & \\
\hline No. of patients (\%) & $56(19.2)$ & $140(48.1)$ & $95(32.6)$ & $<0.001$ & $291(100)$ \\
\hline Female/male ratio & $47: 9$ & $125: 15$ & $69: 24$ & 0.010 & $241: 48$ \\
\hline Mean age, yrs (SD) & $30.6(8.0)$ & $56.4(4.9)$ & $70.9(5.3)$ & $<0.001$ & $56.2(15.2)$ \\
\hline Mean BMI, kg/m² (SD) & $24.4(5.6)$ & $27.5(6.2)$ & $28.8(5.8)$ & $<0.001$ & $27.3(6.1)$ \\
\hline Mean CCI (SD) & $0.3(0.7)$ & $1.4(1.6)$ & $2.1(1.7)$ & $<0.001$ & $1.4(1.6)$ \\
\hline Mean ASA score (SD) & $1.8(0.6)$ & $2.3(0.6)$ & $2.6(0.6)$ & $<0.001$ & $2.3(0.7)$ \\
\hline Current smoker, no. (\%) & $11(19.6)$ & $11(7.9)$ & $3(3.2)$ & 0.001 & $25(8.6)$ \\
\hline Previous spine op, no. (\%) & $12(21.4)$ & $67(47.8)$ & $53(55.8)$ & $<0.001$ & $135(46)$ \\
\hline Previous fusion, no. (\%) & $12(21.4)$ & $52(37.1)$ & $35(36.8)$ & 0.046 & $99(34)$ \\
\hline Anterior procedure, no. (\%) & $3(5.4)$ & $55(39.3)$ & $16(16.8)$ & $<0.001$ & $74(25.4)$ \\
\hline Mean levels, no. (SD) & $4.3(1.5)$ & $3.1(1.3)$ & $3.0(1.3)$ & 0.264 & $3.1(1.3)$ \\
\hline Posterior procedure, no. (\%) & $56(100)$ & $137(97.9)$ & $94(98.9)$ & 0.670 & $287(99)$ \\
\hline Mean levels, no. (SD) & $9.9(3.8)$ & $11.8(4.5)$ & $10.8(4.8)$ & 0.024 & $11.1(4.5)$ \\
\hline Osteotomy, no. (\%) & $28(50.0)$ & $96(68.6)$ & $63(66.3)$ & 0.044 & $187(64.3)$ \\
\hline Pedicle subtraction & $4(7.1)$ & $22(15.7)$ & $21(22.1)$ & 0.053 & $47(16.2)$ \\
\hline Smith-Petersen & $24(42.9)$ & $78(55.7)$ & $45(47.4)$ & 0.201 & $147(50.5)$ \\
\hline Vertebral column & $1(1.8)$ & $5(3.6)$ & $3(3.2)$ & 0.808 & $9(3.1)$ \\
\hline Decompression, no. (\%) & $9(16.1)$ & $90(64.3)$ & $75(78.9)$ & $<0.001$ & $174(59.8)$ \\
\hline Mean OR time, hrs (SD) & $5.4(2.2)$ & $7.7(3.1)$ & $7.3(3.3)$ & $<0.001 \dagger$ & $7.1(3.2)$ \\
\hline Mean EBL, L (SD) & $1.4(1.4)$ & $1.9(1.7)$ & $2.1(1.8)$ & $0.006 t$ & $1.9(1.7)$ \\
\hline Mean LOS, days (SD) & $7.0(4.0)$ & $8.2(4.8)$ & $8.9(5.0)$ & $0.001 \dagger$ & $8.2(4.8)$ \\
\hline
\end{tabular}

without 2-year follow-up had similar mean age (56.2 vs 59.4 years, respectively; $\mathrm{p}=0.16$ ), percentage of women ( $83 \%$ vs $74 \%$, respectively; $p=0.12$ ), percentage with prior spine surgery ( $46 \%$ vs $47 \%$, respectively; $\mathrm{p}=0.88$ ), percentage of current smokers (9\% vs $16 \%$, respectively; $\mathrm{p}=$ $0.19)$, baseline BMI (27.3 vs 27.6, respectively; $p=0.76$ ), baseline CCI (1.43 vs 1.53 , respectively; $\mathrm{p}=0.67)$, and baseline ASA score (2.3 vs 2.4, respectively; $\mathrm{p}=0.19)$. Patients with and without a minimum 2-year follow-up were also similar with regard to deformity types and severities based on the SRS-Schwab curve type descriptor $(\mathrm{p}=0.32)$, PT modifier $(\mathrm{p}=0.19)$, SVA modifier $(\mathrm{p}=0.67)$, and PI-LL modifier $(\mathrm{p}=0.19)$.

\section{Perioperative and Delayed Complications by General Category}

Table 2 summarizes the perioperative and delayed complications by general category among the 291 patients with minimum 2-year follow-up. During the follow-up interval, a total of 82 patients $(28.2 \%)$ patients required 1 or more reoperation. These reoperations were associated with 38 additional perioperative complications (16 minor; 22 major), and these complications are included in Table 2. A total of 270 perioperative complications (145 minor; 125 major) were reported, with a mean number of complications per patient of 0.93 and $52.2 \%$ of patients affected by at least 1 perioperative complication. A total of 199 delayed complications were reported, including 62 minor and 137 major. The mean number of delayed complications per patient was 0.68 , and $42.6 \%$ of patients had 1 or more delayed complications. Overall, 469 complications were reported (207 minor; 262 major), with a mean number of complications per patient of 1.61 and $69.8 \%$ of patients experiencing at least 1 complication at some point during the perioperative time or minimum 2-year followup. Figure 2 summarizes the distribution of patients based on the numbers of minor and major complications that occurred. The most common complications occurring by category were implant-related, radiographic, neurological, operative, cardiopulmonary, and infection (Table 2).

The reported perioperative and delayed complications for the 55 patients who did not reach 2-year follow-up are summarized in Table 3. The mean numbers of total, minor, and major perioperative complications per patient did not differ significantly between those who did and did not achieve a minimum 2-year follow-up ( $\mathrm{p}=0.65,0.68$, and 0.79 , respectively). The percentage of patients affected by 1 or more perioperative complications was also not significantly different among these groups $(\mathrm{p}=0.14)$. As expected, the mean numbers of total, minor, and major delayed complications per patient were significantly lower for those who did not reach a minimum 2-year follow-up compared with those who did $(\mathrm{p}<0.001, \mathrm{p}=0.014$ and 0.002 , respectively). The percentage of patients affected by 1 or more delayed complications was significantly lower for those without a minimum 2-year follow-up (21.8\% 


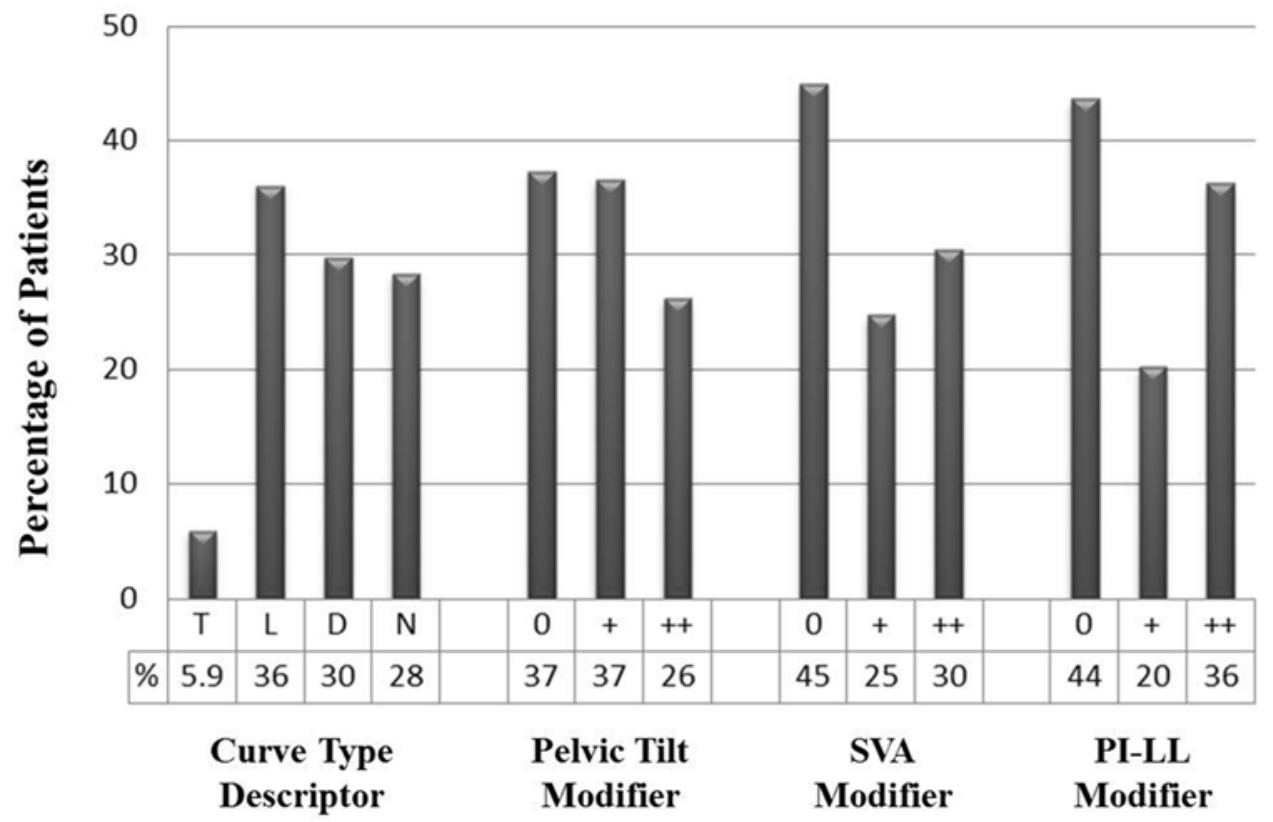

FIG. 1. Distribution of patients in the present study by SRS-Schwab classification curve type descriptor and sagittal spinopelvic modifier classification. ${ }^{42}+=$ moderate malalignment based on indicated measurement; $++=$ severe malalignment based on indicated measurement; PI-LL = pelvic incidence to lumbar lordosis mismatch.

vs $40.5 \%$ ). Although the overall mean number of complications per patient was significantly lower for those without a minimum 2-year follow-up (1.11 vs $1.61 ; \mathrm{p}<0.001)$, there appeared to be less clustering of complications, since the 2 groups had similar numbers of patients affected by 1 or more complications overall ( $70.9 \%$ vs $69.8 \% ; \mathrm{p}=1.00)$ (Tables 2 and 3).

\section{Mortality}

Among the 55 patients who did not achieve 2-year follow-up, there were 2 perioperative deaths, 1 due to pulmonary embolism and 1 due to intraoperative inferior vena cava injury (Table 3). Thus, the perioperative (within 6 weeks of surgery) mortality rate among the 339 patients with at least 6 weeks of follow-up was $0.6 \%$ (approximately 1 per 170). Also in these 55 patients, there were 2 additional deaths, which were not thought to be related to the surgical procedure: 1 case of myocardial infarction and 1 case of aplastic anemia that occurred at approximately 1.9 and 1.6 years following surgery, respectively.

\section{Perioperative and Delayed Complications by Subtype}

Tables 4-7 provide summaries of the subtypes of reported complications for the most common complication

TABLE 2. Rates of complications in 291 patients surgically treated for ASD who had a minimum 2-year follow-up

\begin{tabular}{lccc}
\hline \multirow{2}{*}{ Complication Category } & \multicolumn{3}{c}{ Minor/Major Complications (\%) } \\
\cline { 2 - 4 } & Periop (<6 wks) & Delayed $(>6$ wks) & Total \\
\hline Implant & $3 / 8(3.8)$ & $11 / 59(24.1)$ & $14 / 67(27.8)$ \\
\hline Radiographic & $4 / 10(4.8)$ & $25 / 42(23.0)$ & $29 / 52(27.8)$ \\
\hline Neurological & $21 / 24(15.5)$ & $16 / 20(12.4)$ & $37 / 44(27.8)$ \\
\hline Operative & $41 / 32(25.1)$ & $0 / 1(0.3)$ & $41 / 33(25.4)$ \\
\hline Cardiopulmonary & $31 / 20(17.5)$ & $1 / 3(1.4)$ & $32 / 23(18.9)$ \\
\hline Infection & $11 / 20(10.7)$ & $5 / 7(4.1)$ & $16 / 27(14.8)$ \\
\hline Gastrointestinal & $24 / 1(8.6)$ & $0 / 0(0)$ & $24 / 1(8.6)$ \\
\hline Wound (excluding infection) & $3 / 7(3.4)$ & $0 / 5(1.7)$ & $3 / 12(5.2)$ \\
\hline Vascular & $4 / 0(1.4)$ & $1 / 0(0.3)$ & $5 / 0(1.7)$ \\
\hline Musculoskeletal & $0 / 0(0)$ & $3 / 0(1.0)$ & $3 / 0(1.0)$ \\
\hline Renal & $1 / 2(1.0)$ & $0 / 0(0)$ & $1 / 2(1.0)$ \\
\hline Other & $2 / 1(1.0)$ & $0 / 0(0)$ & $2 / 1(1.0)$ \\
\hline Total (minor/major) & $270(145 / 125)$ & $199(62 / 137)$ & $469(207 / 262)$ \\
\hline Mean no. of complications/patient (minor/major) & $0.93(0.50 / 0.43)$ & $0.68(0.21 / 0.47)$ & $1.61(0.71 / 0.90)$ \\
\hline Number of patients affected (\%) & $152(52.2)$ & $124(42.6)$ & $203(69.8)$ \\
\hline
\end{tabular}




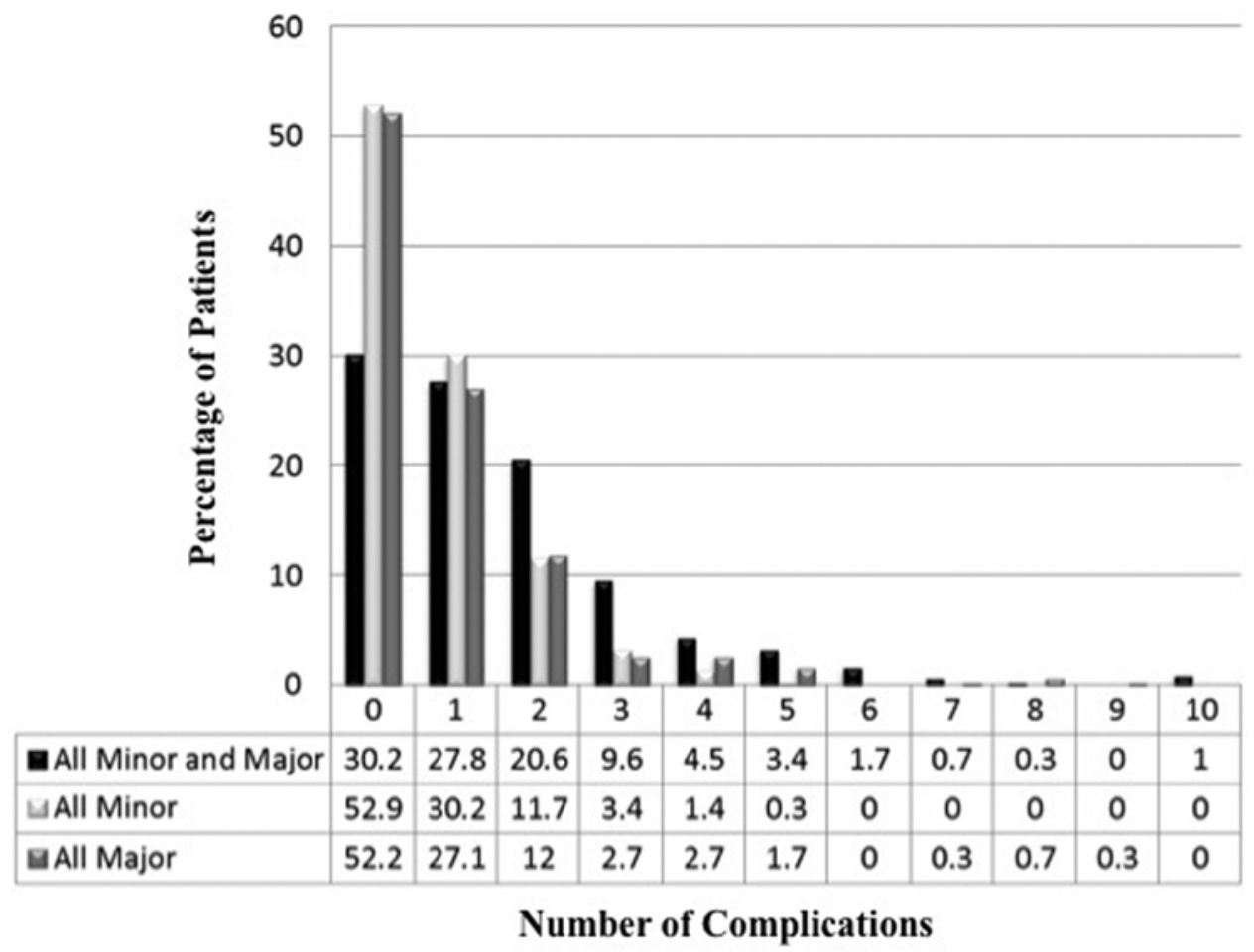

FIG. 2. Distribution of patients based on the numbers of minor and major complications that occurred. Complications include those occurring intraoperatively through the minimum 2-year follow-up period.

categories from Table 2. The most common implant and radiographic complications were rod breakage and PJK, respectively (Table 4). Although rod breakage is often presumed to reflect pseudarthrosis, we chose to report the two separately. Patients who presented with a rod breakage were reported as having a rod breakage complication and not necessarily as also having pseudarthrosis (although this may be presumed for the vast majority of the cases). The reporting of pseudarthrosis as a complication was based on radiographic review. Of note, 4 of the 39 patients who

TABLE 3. Rates of complications in 55 patients surgically treated for ASD who did not have a minimum 2-year follow-up*

\begin{tabular}{lccc}
\hline \multirow{2}{*}{ Complication Category } & \multicolumn{3}{c}{ Minor/Major Complications (\%) } \\
\cline { 2 - 4 } & Periop $(\leq 6 \mathrm{wks})$ & Delayed $(>6$ wks) & Total \\
\hline Implant & $0 / 3(5.5)$ & $0 / 4(7.3)$ & $4 / 3(12.7)$ \\
\hline Radiographic & $0 / 0(0)$ & $4 / 3(12.7)$ & $1 / 6(12.7)$ \\
\hline Neurological & $1 / 6(12.7)$ & $0 / 0(0)$ & $9 / 7(29.1)$ \\
\hline Operative & $9 / 7(29.1)$ & $0 / 0(0)$ & $6 / 6(21.8)$ \\
\hline Cardiopulmonary & $6 / 6 \dagger(21.8)$ & $0 / 0(0)$ & $1 / 2(5.5)$ \\
\hline Infection & $1 / 1(3.6)$ & $0 / 1(1.8)$ & $6 / 0(10.9)$ \\
\hline Gastrointestinal & $6 / 0(10.9)$ & $0 / 0(0)$ & $0 / 0(0)$ \\
\hline Wound (excluding infection) & $0 / 0(0)$ & $0 / 0(0)$ & $0 / 1(1.8)$ \\
\hline Vascular & $0 / 1 \ddagger(1.8)$ & $0 / 0(0)$ & $0 / 1(1.8)$ \\
\hline Musculoskeletal & $0 / 0(0)$ & $0 / 1(1.8)$ & $0 / 0(0)$ \\
\hline Renal & $0 / 0(0)$ & $0 / 0(0)$ & $1 / 0(1.8)$ \\
\hline Other & $1 / 0(1.8)$ & $0 / 0(0)$ & $61(28 / 33)$ \\
\hline Total (minor/major) & $48(24 / 24)$ & $13(4 / 9)$ & $1.11(0.51 / 0.60)$ \\
\hline Mean no. of complications/patient (minor/major) & $0.87(0.44 / 0.44)$ & $0.24(0.07 / 0.16)$ & $39(70.9)$ \\
\hline No. of patients affected (\%) & $35(63.6)$ & $13(23.6)$ & \\
\hline
\end{tabular}

* Mean follow-up was 0.57 years. No follow-up beyond discharge was reported for 7 patients, 19 had no follow-up beyond 6 weeks, and 29 had no follow-up beyond 1 year.

$\dagger$ One of the perioperative major complications was a fatal pulmonary embolism.

$\ddagger$ The major perioperative vascular complication was an injury to the inferior vena cava resulting in death. 
TABLE 4. Rates of implant and radiographic complications in 291 patients surgically treated for ASD who had a minimum 2-year follow-up*

\begin{tabular}{|c|c|c|c|}
\hline \multirow[b]{2}{*}{ Complication Categories \& Subgroups } & \multicolumn{3}{|c|}{ Minor/Major Complications (\%) } \\
\hline & Periop ( $\leq 6$ wks) & Delayed (>6 wks) & Total \\
\hline Implant & $3 / 8(3.8)$ & $11 / 59(24.1)$ & $14 / 67(27.8)$ \\
\hline Rod breakage & 0/1 (1 reop) & 0/39 (14 reop) & $0 / 40(13.7)$ \\
\hline Implant prominence & $0 / 1$ & 6/4 (4 reop) & $6 / 5(3.8)$ \\
\hline Painful implant & $0 / 0$ & $2 / 5$ (5 reop) & $2 / 5(2.4)$ \\
\hline Screw breakage & $0 / 1$ & 0/5 (1 reop) & $0 / 6(2.1)$ \\
\hline Screw loosening & 1/1 (1 reop) & $3 / 1$ & $4 / 2(2.1)$ \\
\hline Interbody spacer dislodgment & 0/2 (1 reop) & $0 / 1$ & $0 / 3(1.0)$ \\
\hline Screw medial breach & $1 / 0$ & 0/1 (1 reop) & $1 / 1(0.7)$ \\
\hline Implant failure & $0 / 0$ & 0/1 (1 reop) & $0 / 1(0.3)$ \\
\hline Rod dislodgment & $0 / 0$ & 0/1 (1 reop) & $0 / 1(0.3)$ \\
\hline Screw dislodgment & $0 / 0$ & 0/1 (1 reop) & $0 / 1(0.3)$ \\
\hline Crosslink dislodgment & $1 / 0$ & $0 / 0$ & $1 / 0(0.3)$ \\
\hline Fixation failure & 0/1 (1 reop) & $0 / 0$ & $0 / 1(0.3)$ \\
\hline Hook dislodgment & $0 / 1$ & $0 / 0$ & $0 / 1(0.3)$ \\
\hline Screw nerve impinge & $0 / 0$ & $0 / 0$ & $0 / 0(0.0)$ \\
\hline Screw vascular impingement & $0 / 0$ & $0 / 0$ & $0 / 0(0.0)$ \\
\hline Radiographic & $4 / 10(4.8)$ & $25 / 42(23.0)$ & $29 / 52(27.8)$ \\
\hline PJK & $3 / 8$ (6 reop) & 15/13 (12 reop) & $18 / 21(13.4)$ \\
\hline Pseudarthrosis & $0 / 0$ & 0/15 (10 reop) & $0 / 15(5.2)$ \\
\hline Adjacent-segment disease & $0 / 0$ & 6/4 (2 reop) & $6 / 4(3.4)$ \\
\hline Coronal imbalance & $1 / 2$ (2 reop) & $3 / 2$ (2 reop) & $4 / 4(2.7)$ \\
\hline Sagittal imbalance & $0 / 0$ & 1/4 (3 reop) & $1 / 4(1.7)$ \\
\hline Distal junctional kyphosis & $0 / 0$ & 0/4 (2 reop) & $0 / 4(1.4)$ \\
\hline
\end{tabular}

* The number of reoperations indicates the subset of indicated major complications that were associated with the need for reoperation.

presented with a rod fracture had been previously reported as having a radiographic pseudarthrosis. The most common neurological complications were radiculopathy and motor and sensory deficits (Table 5). Anemia/excessive blood loss and dural tear were the most common operative complications, and pleural effusion was the most common cardiopulmonary complication (Table 6). Deep wound infections and wound dehiscence were the most common

TABLE 5. Rates of neurological complications in 291 patients surgically treated for ASD who had a minimum 2-year follow-up*

\begin{tabular}{cccc}
\hline & \multicolumn{3}{c}{ Minor/Major Complications (\%) } \\
\cline { 2 - 4 } Complication Category \& Subgroups & Periop (<6 wks) & Periop (<6 wks) & Periop (<6 wks) \\
\hline Neurological & $21 / 24(15.5)$ & $16 / 20(12.4)$ & $37 / 44(27.8)$ \\
\hline Radiculopathy & $3 / 6(3 \mathrm{reop})$ & $10 / 7(4 \mathrm{reop})$ & $0 / 14(4.8)$ \\
\hline Motor deficit & $0 / 7(2 \mathrm{reop})$ & $0 / 7(5 \mathrm{reop})$ & $8 / 3(3.8)$ \\
\hline Sensory deficit & $4 / 0$ & $4 / 3(3 \mathrm{reop})$ & $3 / 5(2.7)$ \\
\hline Nerve root injury & $3 / 4(2$ reop) & $0 / 1$ & $5 / 0(1.7)$ \\
\hline Mental status change & $5 / 0$ & $0 / 0$ & $0 / 2(0.7)$ \\
\hline Stroke & $0 / 1$ & $0 / 1$ & $0 / 2(0.7)$ \\
\hline Bowel/bladder deficit & $0 / 2$ & $0 / 0$ & $2 / 0(0.7)$ \\
\hline Femoral neuralgia & $2 / 0$ & $0 / 0$ & $0 / 1(0.3)$ \\
\hline Myelopathy & $0 / 0$ & $0 / 1(1 \mathrm{reop})$ & $0 / 1(0.3)$ \\
\hline Peroneal nerve palsy & $0 / 1$ & $0 / 0$ & $0 / 0(0.0)$ \\
\hline Epidural hematoma & $0 / 0$ & $0 / 0$ & $6 / 3(3.1)$ \\
\hline Other & $4 / 3(1$ reop) & $2 / 0$ & \\
\hline
\end{tabular}

\footnotetext{
* The number of reoperations indicates the subset of indicated major complications that were associated with the need for reoperation.
} 
TABLE 6. Rates of operative and cardiopulmonary complications in 291 patients surgically treated for ASD who had a minimum 2-year follow-up*

\begin{tabular}{cccc}
\hline & \multicolumn{3}{c}{ Minor/Major Complications (\%) } \\
\cline { 2 - 4 } Complication Categories \& Subgroups & Periop $(\leq 6 \mathrm{wks})$ & Delayed $(>6 \mathrm{wks})$ & Total \\
\hline Operative & $41 / 32(25.1)$ & $0 / 1(0.3)$ & $41 / 33(25.4)$ \\
\hline Anemia/excessive blood loss & $6 / 26$ & $0 / 0$ & $6 / 26(11.0)$ \\
\hline Dural tear & $30 / 1$ & $0 / 0$ & $30 / 1(10.7)$ \\
\hline Monitoring anomaly & $4 / 4$ & $0 / 0$ & $4 / 4(2.7)$ \\
\hline Bowel perforation & $0 / 1$ & $0 / 0$ & $0 / 1(0.3)$ \\
\hline Pedicle fracture & $0 / 0$ & $0 / 1$ & $0 / 1(0.3)$ \\
\hline Vertebra fracture & $1 / 0$ & $0 / 0$ & $1 / 0(0.3)$ \\
\hline Vascular injury & $0 / 0$ & $0 / 0$ & $0 / 0(0.0)$ \\
\hline Other & $0 / 0$ & $0 / 0$ & $0 / 0(0.0)$ \\
\hline Cardiopulmonary & $31 / 20(17.5)$ & $1 / 3(1.4)$ & $32 / 23(18.9)$ \\
\hline Pleural effusion & $21 / 1(1$ reop $)$ & $0 / 1$ & $21 / 2(7.9)$ \\
\hline Arrhythmia & $5 / 1$ & $1 / 0$ & $6 / 1(2.4)$ \\
\hline Pulmonary other & $3 / 4$ & $0 / 0$ & $3 / 4(2.4)$ \\
\hline Pulmonary embolism & $0 / 5$ & $0 / 1$ & $0 / 6(2.1)$ \\
\hline Deep venous thrombosis & $0 / 6$ & $0 / 0$ & $0 / 6(2.1)$ \\
\hline Congestive heart failure & $0 / 0$ & $0 / 1$ & $0 / 1(0.3)$ \\
\hline Myocardial infarction & $0 / 1$ & $0 / 0$ & $0 / 1(0.3)$ \\
\hline Reintubation & $0 / 1$ & $0 / 0$ & $0 / 1(0.3)$ \\
\hline ARDS & $0 / 0$ & $0 / 0$ & $0 / 0(0.0)$ \\
\hline Cardiac arrest & $0 / 0$ & $0 / 0$ & $0 / 0(0.0)$ \\
\hline Cardiopulmonary failure & $0 / 0$ & $0 / 0$ & $0 / 0(0.0)$ \\
\hline Other & $2 / 1$ & $0 / 0$ & $2 / 1(1.0)$ \\
\hline
\end{tabular}

ARDS = acute respiratory distress syndrome.

* The number of reoperations indicates the subset of indicated major complications that were associated with the need for reoperation.

infection and wound complications (excluding infection), respectively (Table 7). The most common gastrointestinal complication was postoperative ileus, accounting for 22 $(88 \%)$ of the complications in this category (Table 2).

\section{Assessment of Factors Associated With Complication Occurrence}

Factors assessed for association with the occurrence of complications are summarized in Table 8. Patients affect-

TABLE 7. Rates of infection and wound complications in 291 patients surgically treated for ASD who had a minimum 2-year follow-up*

\begin{tabular}{|c|c|c|c|}
\hline \multirow[b]{2}{*}{ Complication Categories \& Subgroups } & \multicolumn{3}{|c|}{ Minor/Major Complications (\%) } \\
\hline & Periop ( $\leq 6$ wks) & Delayed (>6 wks) & Total \\
\hline Infection & $11 / 20(10.7)$ & $5 / 7(4.1)$ & $16 / 27(14.8)$ \\
\hline Deep wound infection & 0/11 (8 reop) & 0/7 (5 reop) & $0 / 18(6.2)$ \\
\hline Urinary tract infection & $7 / 0$ & $1 / 0$ & $8 / 0(2.7)$ \\
\hline Pneumonia & $0 / 4$ & $0 / 0$ & $0 / 4(1.4)$ \\
\hline Superficial & $2 / 1$ & $1 / 0$ & $3 / 1(1.4)$ \\
\hline Sepsis & $0 / 3$ & $0 / 0$ & $0 / 3(1.0)$ \\
\hline Other & 2/1 (1 reop) & $3 / 0$ & $5 / 1(2.1)$ \\
\hline Wound, excluding infection & $3 / 7(3.4)$ & $0 / 5(1.7)$ & $3 / 12(5.2)$ \\
\hline Dehiscence & $1 / 5$ (4 reop) & 0/4 (4 reop) & $1 / 9(3.4)$ \\
\hline Erythema & $1 / 1$ & $0 / 0$ & $1 / 1(0.7)$ \\
\hline Hematoma & 0/1 (1 reop) & $0 / 0$ & $0 / 1(0.3)$ \\
\hline Incisional hernia & $0 / 0$ & $0 / 1$ & $0 / 1(0.3)$ \\
\hline Other & $1 / 0$ & $0 / 0$ & $1 / 0(0.3)$ \\
\hline
\end{tabular}

* The number of reoperations indicates the subset of indicated major complications that were associated with the need for reoperation. 
TABLE 8. Overall rates of perioperative (within 6 weeks of surgery) and delayed ( $>6$ weeks after surgery to minimum 2-year follow-up) complications stratified by demographic and surgical parameters*

\begin{tabular}{|c|c|c|c|c|c|c|}
\hline \multirow[b]{2}{*}{ Parameter } & \multicolumn{3}{|c|}{ Periop Complications } & \multicolumn{3}{|c|}{ Delayed Complications } \\
\hline & No & Yes & p Value & No & Yes & $\mathrm{p}$ Value \\
\hline Female (\%) & 47.7 & 52.3 & 0.255 & 58.5 & 41.5 & 0.428 \\
\hline Mean BMI, $\mathrm{kg} / \mathrm{m}^{2}$ (SD) & $26.3(5.9)$ & $28.2(6.2)$ & 0.015 & $26.6(6.3)$ & $28.2(5.8)$ & 0.031 \\
\hline Mean CCl (SD) & $1.1(1.4)$ & $1.7(1.7)$ & 0.002 & $1.2(1.5)$ & $1.7(1.7)$ & 0.007 \\
\hline Mean ASA score (SD) & $2.3(0.7)$ & $2.3(0.6)$ & 0.405 & $2.2(0.7)$ & $2.4(0.6)$ & 0.006 \\
\hline Current smoker (\%) & 44.0 & 56.0 & 0.680 & 56.0 & 44.0 & 1.000 \\
\hline Previous spine surgery (\%) & 48.5 & 51.5 & 1.000 & 52.3 & 47.7 & 0.095 \\
\hline Previous spine fusion (\%) & 44.5 & 55.5 & 0.029 & 54.5 & 45.5 & 1.000 \\
\hline Combined A-P procedure (\%) & 43.8 & 56.2 & 0.417 & 56.2 & 43.8 & 0.891 \\
\hline 3-column osteotomy (\%) & 37.5 & 62.5 & 0.075 & 44.6 & 55.3 & 0.036 \\
\hline
\end{tabular}

A-P = anterior-posterior.

* A perioperative complication is defined as one occurring within 6 weeks of surgery and a delayed complication as one occurring more than 6 weeks to a minimum of 2 years after surgery.

$\dagger$ Boldface type indicates statistical significance.

ed by perioperative complications had significantly higher BMI and CCI values ( $p=0.015$ and $p=0.002$, respectively) and had a significantly greater percentage of patients with history of spine fusion $(p=0.029)$. Patients affected by delayed complications had a significantly higher BMI, CCI, and ASA score ( $p=0.031,0.007$, and 0.006 , respectively) and were more likely to have undergone a 3-column osteotomy ( $p=0.036)$. Notably, factors not associated with perioperative or delayed complications in this cohort included sex, current smoking status, any previous spine surgery, and performance of a combined anterior-posterior procedure $(\mathrm{p} \geq 0.095)$ (Table 8$)$.

Compared with younger patients, a significantly greater proportion of older patients experienced at least 1 complication in the perioperative and/or follow-up time period ( $\mathrm{p}$ $=0.009$ ) (Fig. 3). While there was no significant difference in the percentages of patients affected by 1 or more minor complication based on age $(\mathrm{p}=0.61)$, older patients were significantly more likely to experience 1 or more major complications in the perioperative and/or follow-up time period $(\mathrm{p}=0.009)$ (Fig. 3). Patients at least 45 years of age had a significantly greater mean number of overall complications $(p=0.034)$ and had a significantly greater mean number of delayed complications $(p=0.010)$ compared with patients younger than 45 years of age (Fig. 4). The mean number of major complications was significantly higher for the oldest patient group compared with the youngest (1.08 vs 0.57; $\mathrm{p}=0.024$ ) (Fig. 4).

\section{Discussion}

This study provides an assessment of the complications associated with surgery for ASD based on a prospective, multicenter design with a minimum 2-year follow-up. Standardized data-collection forms, on-site study coordinators, and regular central auditing helped ensure the completeness of complication-data collection. Previous studies that have reported complications for ASD surgery have been limited by many factors, including retrospective design, inclusion of cases from only a single surgeon or single center, inclusion of only short-term complications, limited or poor patient follow-up, and lack of a meticulous or focused effort on recording of complications. ${ }^{6,14,17,22,30,39,47,51,52,55,58}$ The present study was designed in an attempt to overcome these limitations, and, in doing so, has provided likely the most complete and detailed reporting of perioperative and delayed ASD surgery complications to date. The findings may prove useful for treatment planning, patient counseling, benchmarking of complication rates, and efforts to improve the safety of patient care. In addition, these findings may prove useful as a basis for future studies designed to assess the clinical and cost impact of complications. ${ }^{28,29,33}$

Reflective of the length of follow-up and study design, the numbers and rates of complications identified in the present study are substantially higher than those of previous reports. Overall, a total of 469 complications (207 minor and 262 major) at a minimum of 2 years of followup were identified, and $69.8 \%$ of patients were affected by 1 or more complications. In interpreting these findings, it is important to recognize that not all complications are equally impactful ${ }^{14}$ and that many, if not most, likely have minimal or no effect on ultimate patient outcome. However, it is also important to recognize that some of the complications that do not impact long-term outcome may have impact on length of hospital stay, need for invasive procedures (including reoperation), and the rates at which patients recover. ${ }^{26,40}$ In addition, from a societal and payer cost perspective, some complications may increase cost without significantly impacting ultimate patient outcome. Furthermore, some adverse events are so common that they may be accepted as part of the procedure and perhaps should not be termed "complications"; for example, the occurrence of a CSF leak during a revision procedure in a patient with a pseudomeningocele.

Perhaps the greatest value that comes from documenting and assessing the complications associated with a surgical procedure is the ability to develop techniques and approaches to reduce the occurrence of specific complications. The most common complications in the present study, accounting for $88 \%$ of the total complications, were concentrated in 1 of 6 complication categories: implant, radiographic, neurological, operative, cardiopulmonary, 


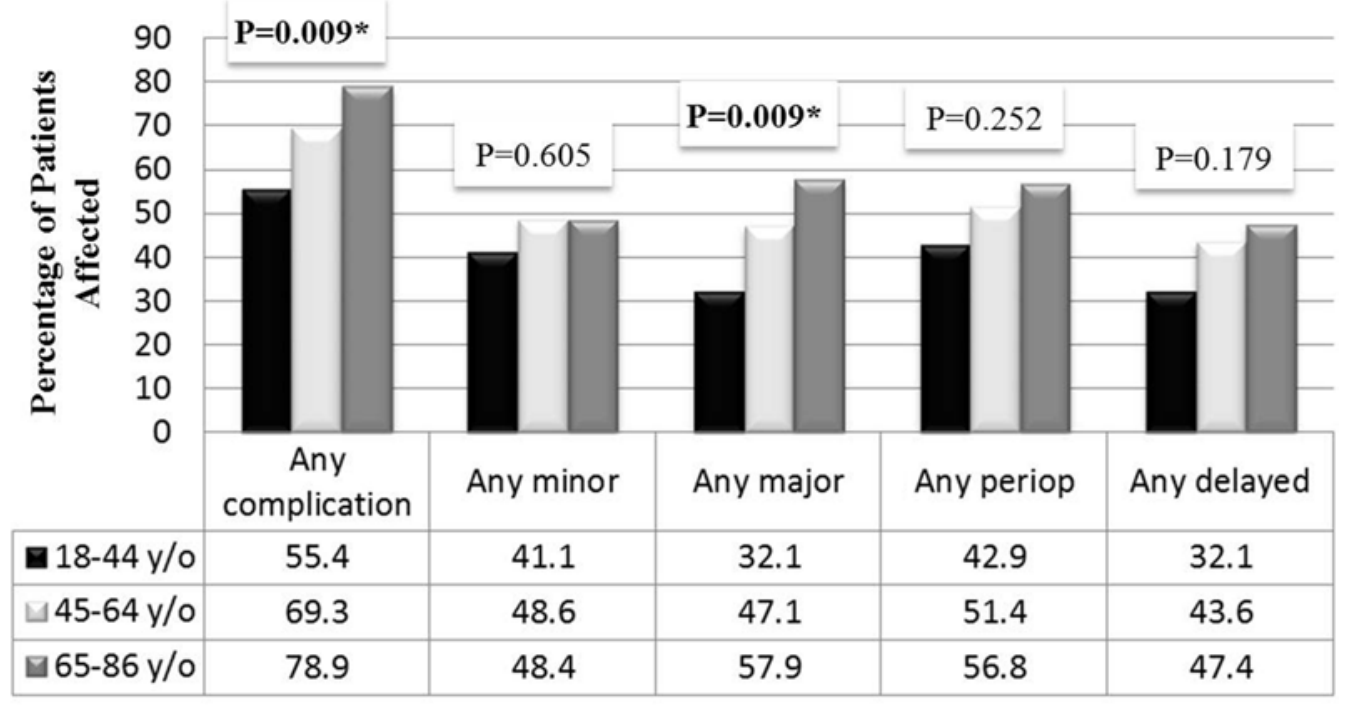

\section{Type of Complication}

FIG. 3. Distribution of 291 adults who underwent ASD surgery and who had a minimum 2-year follow-up stratified based on age group and by percentages of patients affected by any complication and by any minor, major, perioperative (within 6 weeks of surgery), or delayed (between 6 weeks after surgery and last follow-up) complications. Significant $p$ values are shown in boldface. $\mathrm{y} / \mathrm{o}=$ years old

and infection (Table 2). Even since the time of initiation of enrollment for the present study, advances have been made by our group and others to help reduce the occurrence of complications in these categories, and it is likely that the rates of many of the reported complications are currently lower, based on these advances. There are several examples of these improvements. Implant-related complications accounted for $26 \%$ of all major complications, and

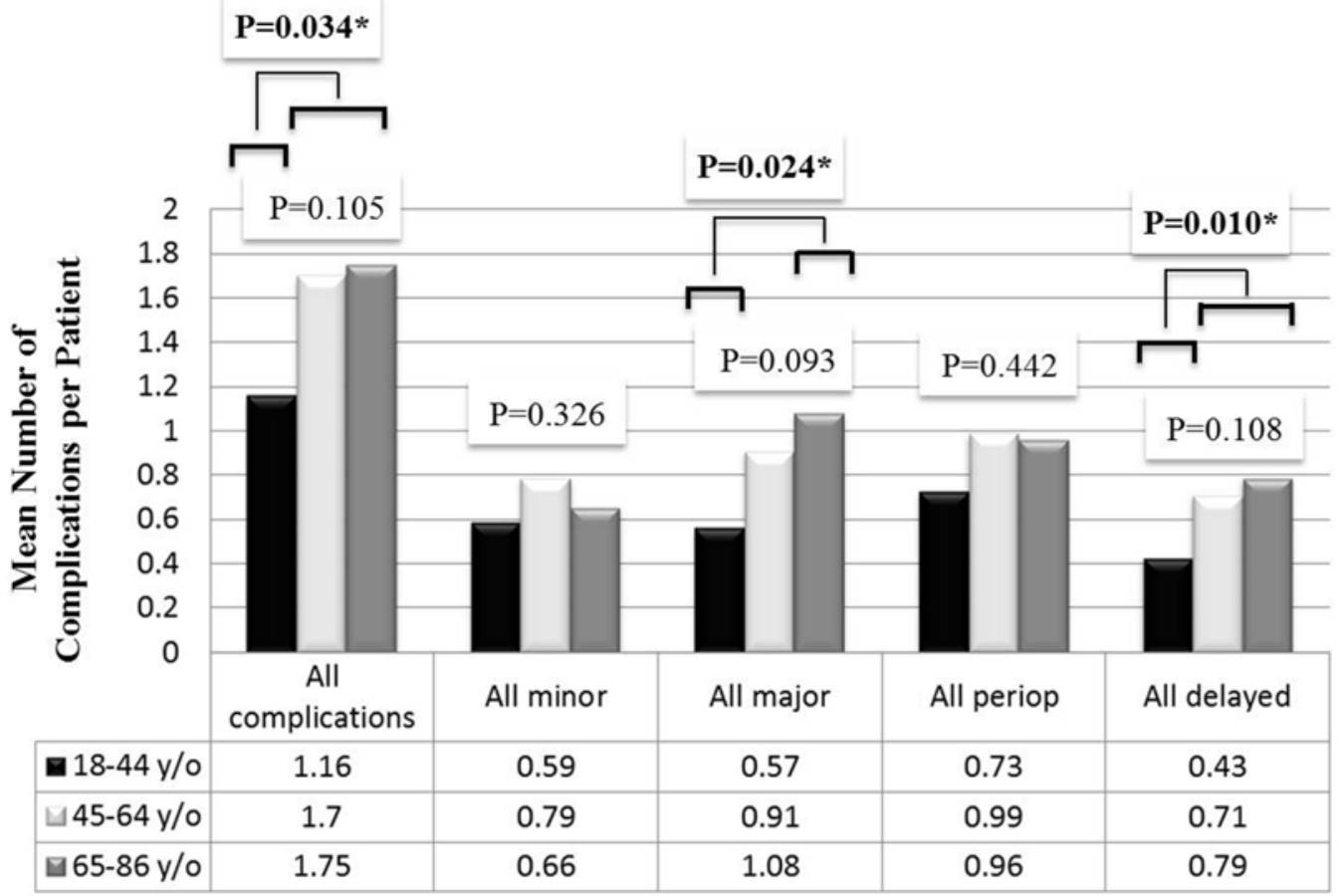

\section{Type of Complication}

FIG. 4. Mean numbers of complications per patient (all, minor, major, perioperative, and delayed) for 291 adults who underwent ASD surgery and who had a minimum 2-year follow-up stratified based on age group. The $p$ values shown reflect comparison of all 3 age groups unless otherwise indicated. Significant $p$ values are shown in boldface. 
the most common implant-related complication by far was rod breakage. Already this complication has been reduced through recognition of the risk factors for its occurrence and through pioneering efforts of Gupta and colleagues in developing multi-rod construct strategies (M. Gupta et al., unpublished data, 2015). ${ }^{19,52,59,62}$ Radiographic complications accounted for $20 \%$ of all major complications, and the most common radiographic complication by far was development of PJK. Substantial progress has been made in defining optimal radiographic alignment parameters to help reduce the risk for this complication ${ }^{2,16,23,27,43}$ and a classification has been developed to better appreciate factors associated with the need for revision surgery. ${ }^{24} \mathrm{Op}$ erative complications accounted for $13 \%$ of all major complications, and the most common operative complication was anemia/excessive blood loss. Multiple studies have demonstrated the potential effectiveness of intraoperative antifibrinolytic therapy in significantly reducing blood loss (A. Soroceanu et al., unpublished data).9,36,65 In addition, a recently published application of rotational thromboelastometry-guided blood product management to major spine procedures suggests that this technology may aid in reducing blood loss, blood product use, and cost. ${ }^{31}$ Infections accounted for $9 \%$ of all major complications, and deep wound infection was the most common infection. Multiple publications have advanced the use of intrawound vancomycin powder as a potentially effective means of reducing deep wound infections..$^{20,64}$

It is well recognized that older patients face greater risk for complications with ASD surgery. ${ }^{22,49,55,66,67}$ The present study confirms this observation and provides potentially useful benchmarking data for expected complication rates based on patient age. While the rate of overall minor complications was similar across all 3 age groups assessed, the rate of major complications was progressively greater from the young to the middle-age to the elderly patient groups, suggesting that the elderly may be most vulnerable to the more serious complications. Other risk factors for complication occurrence identified in the present study included greater BMI, worse comorbidities, previous spine fusion, and need for 3-column osteotomy. Many of these have also been suggested in previous reports. 4,12,39,45,46,50-52,55,58,59

Minimum 2-year follow-up was achieved in $84 \%$ of patients in the present study, which is comparable to previous reports of outcomes for ASD surgery. ${ }^{6,53-55}$ Of the 55 patients who did not achieve 2-year follow-up, there were 4 deaths: 2 in the perioperative period and 2 thought to not be related to the surgical procedure. Reasons for the remaining 51 patients to not complete 2-year follow-up are unknown. To determine whether a primary reason for lack of follow-up may be due to the occurrence of complications, we have provided separate assessment of the perioperative and delayed complications in this patient group. The types and overall rates of perioperative complications were similar between those who did and did not achieve 2-year follow-up, and there did not appear to be an inordinate number or representation of particularly severe delayed complications in the patients lost to follow-up. Thus, it does not appear that that occurrence of complications is a primary factor for lack of patient follow-up.

Strengths of the present study include the prospective multicenter design, use of standardized data-collection sheets, presence of on-site study coordinators, regular auditing of data, and the length of follow-up. Limitations of the present study include the limited ability to detect some occult complications. For example, since many sites do not obtain routine CT imaging at follow-up, assessment of complications such as medial screw breaches and pseudarthrosis was limited to the clinically significant cases. Reported medial screw breaches were those that were significant enough to prompt exploration and/or revision. The reporting of painful implant complications was based on patient evaluation by the surgeon and is limited by the lack of specific assessment of symptoms following reoperation. Since a common hematocrit level below which the patient was diagnosed with acute blood-loss anemia was not established, the resulting incidence of this complication is likely an underestimate. Reported pseudarthrosis complications were primarily those in which there was instrumentation failure and/or evidence of frank nonunion on plain radiographs. In addition, in the present study, we do not provide assessment of complication impact on patient outcomes, as this is beyond the scope of the present study and will be the subject of future efforts.

\section{Conclusions}

This study provides an assessment of the complications associated with ASD surgery based on a prospective, multicenter design with a minimum 2-year follow-up. Among 291 patients, 270 perioperative complications (145 minor; 125 major) were documented, and $52.2 \%$ of patients were affected by 1 or more of these complications. A total of 199 delayed complications were reported (62 minor; 137 major), and $42.6 \%$ of patients had 1 or more of these complications. The most common complications were implant related, radiographic, neurological, operative, cardiopulmonary, and infection. To our knowledge, this study represents 1 of the most complete and detailed reports of perioperative and delayed ASD surgery complications to date. These findings may prove useful for treatment planning, patient counseling, benchmarking of complication rates, and efforts to improve the safety of patient care.

\section{References}

1. Aebi M: The adult scoliosis. Eur Spine J 14:925-948, 2005

2. Ames CP, Smith JS, Scheer JK, Bess S, Bederman SS, Deviren $\mathrm{V}$, et al: Impact of spinopelvic alignment on decision making in deformity surgery in adults: a review. J Neurosurg Spine 16:547-564, 2012

3. Bess S, Line B, Fu KM, McCarthy I, Lafage V, Schwab F, et al: The health impact of symptomatic adult spinal deformity: comparison of deformity types to United States population norms and chronic disease. Spine (Phila Pa 1976) [epub ahead of print], 2015

4. Booth KC, Bridwell KH, Lenke LG, Baldus CR, Blanke KM: Complications and predictive factors for the successful treatment of flatback deformity (fixed sagittal imbalance). Spine (Phila Pa 1976) 24:1712-1720, 1999

5. Bridwell KH, Baldus C, Berven S, Edwards C II, Glassman $\mathrm{S}$, Hamill C, et al: Changes in radiographic and clinical outcomes with primary treatment adult spinal deformity surgeries from two years to three- to five-years follow-up. Spine (Phila Pa 1976) 35:1849-1854, 2010 
6. Bridwell KH, Glassman S, Horton W, Shaffrey C, Schwab F, Zebala LP, et al: Does treatment (nonoperative and operative) improve the two-year quality of life in patients with adult symptomatic lumbar scoliosis: a prospective multicenter evidence-based medicine study. Spine (Phila Pa 1976) 34:2171-2178, 2009

7. Carter OD, Haynes SG: Prevalence rates for scoliosis in US adults: results from the first National Health and Nutrition Examination Survey. Int J Epidemiol 16:537-544, 1987

8. Champain S, Benchikh K, Nogier A, Mazel C, Guise JD, Skalli W: Validation of new clinical quantitative analysis software applicable in spine orthopaedic studies. Eur Spine J 15:982-991, 2006

9. Cheriyan T, Maier SP II, Bianco K, Slobodyanyuk K, Rattenni RN, Lafage V, et al: Efficacy of tranexamic acid on surgical bleeding in spine surgery: a meta-analysis. Spine J 15:752-761, 2015

10. Francis RS: Scoliosis screening of 3,000 college-aged women. The Utah Study-phase 2. Phys Ther 68:1513-1516, 1988

11. Fu KM, Rhagavan P, Shaffrey CI, Chernavvsky DR, Smith JS: Prevalence, severity, and impact of foraminal and canal stenosis among adults with degenerative scoliosis. Neurosurgery 69:1181-1187, 2011

12. Fu KM, Smith JS, Polly DW Jr, Ames CP, Berven SH, Perra $\mathrm{JH}$, et al: Correlation of higher preoperative American Society of Anesthesiology grade and increased morbidity and mortality rates in patients undergoing spine surgery. J Neurosurg Spine 14:470-474, 2011

13. Fu KM, Smith JS, Sansur CA, Shaffrey CI: Standardized measures of health status and disability and the decision to pursue operative treatment in elderly patients with degenerative scoliosis. Neurosurgery 66:42-47, 2010

14. Glassman SD, Hamill CL, Bridwell KH, Schwab FJ, Dimar JR, Lowe TG: The impact of perioperative complications on clinical outcome in adult deformity surgery. Spine (Phila Pa 1976) 32:2764-2770, 2007

15. Guler UO, Cetin E, Yaman O, Pellise F, Casademut AV, Sabat MD, et al: Sacropelvic fixation in adult spinal deformity (ASD); a very high rate of mechanical failure. Eur Spine J 24:1085-1091, 2015

16. Gupta M, Henry JK, Schwab F, Klineberg E, Smith JS, Gum J, et al: Dedicated spine measurement software quantifies key spino-pelvic parameters more reliably than traditional picture archiving and communication systems tools. Spine (Phila Pa 1976) 41:E22-E27, 2016

17. Hamilton DK, Smith JS, Sansur CA, Glassman SD, Ames CP, Berven SH, et al: Rates of new neurological deficit associated with spine surgery based on 108,419 procedures: a report of the scoliosis research society morbidity and mortality committee. Spine (Phila Pa 1976) 36:1218-1228, 2011

18. Hart RA, Cabalo A, Bess S, Akbarnia BA, Boachie-Adjei O, Burton D, et al: Comparison of patient and surgeon perceptions of adverse events after adult spinal deformity surgery. Spine (Phila Pa 1976) 38:732-736, 2013

19. Hyun SJ, Lenke LG, Kim YC, Koester LA, Blanke KM: Comparison of standard 2-rod constructs to multiple-rod constructs for fixation across 3-column spinal osteotomies. Spine (Phila Pa 1976) 39:1899-1904, 2014

20. Kang DG, Holekamp TF, Wagner SC, Lehman RA Jr: Intrasite vancomycin powder for the prevention of surgical site infection in spine surgery: a systematic literature review. Spine J 15:762-770, 2015

21. Kostuik JP, Bentivoglio J: The incidence of low back pain in adult scoliosis. Acta Orthop Belg 47:548-559, 1981

22. La Maida GA, Luceri F, Gallozzi F, Ferraro M, Bernardo M: Complication rate in adult deformity surgical treatment: safety of the posterior osteotomies. Eur Spine J 24 (Suppl 7):879-886, 2015

23. Lafage R, Schwab F, Challier V, Henry JK, Gum J, Smith J, et al: Defining spino-pelvic alignment thresholds: should operative goals in adult spinal deformity surgery account for age? Spine (Phila Pa 1976) 41:62-68 2016

24. Lau D, Funao H, Clark AJ, Nicholls F, Smith J, Bess S, et al: The clinical correlation of the Hart-ISSG proximal junctional kyphosis severity scale with health-related quality-of-life outcomes and need for revision surgery. Spine (Phila Pa 1976) [epub ahead of print], 2015

25. Liu S, Schwab F, Smith JS, Klineberg E, Ames CP, Mundis $\mathrm{G}$, et al: Likelihood of reaching minimal clinically important difference in adult spinal deformity: a comparison of operative and nonoperative treatment. Ochsner J 14:67-77, 2014

26. Liu S, Tetreault L, Fehlings MG, Challier V, Smith JS, Shaffrey CI, et al: A novel method using baseline normalization and area under the curve to evaluate differences in outcome between treatment groups and application to patients with cervical spondylotic myelopathy undergoing anterior versus posterior surgery. Spine (Phila Pa 1976) 40:E1299-E1304, 2015

27. Maggio D, Ailon TT, Smith JS, Shaffrey CI, Lafage V, Schwab F, et al: Assessment of impact of standing longcassette radiographs on surgical planning for lumbar pathology: an international survey of spine surgeons. J Neurosurg Spine 23:581-588, 2015

28. McCarthy I, Hostin R, O’Brien M, Saigal R, Ames CP: Health economic analysis of adult deformity surgery. Neurosurg Clin N Am 24:293-304, 2013

29. McCarthy IM, Hostin RA, Ames CP, Kim HJ, Smith JS, Boachie-Adjei O, et al: Total hospital costs of surgical treatment for adult spinal deformity: an extended follow-up study. Spine J 14:2326-2333, 2014

30. Mok JM, Cloyd JM, Bradford DS, Hu SS, Deviren V, Smith JA, et al: Reoperation after primary fusion for adult spinal deformity: rate, reason, and timing. Spine (Phila Pa 1976) 34:832-839, 2009

31. Naik BI, Pajewski TN, Bogdonoff DI, Zuo Z, Clark P, Terkawi AS, et al: Rotational thromboelastometry-guided blood product management in major spine surgery. J Neurosurg Spine 23:239-249, 2015

32. O'Brien M, Kuklo TR, Blanke KM, Lenke LG (eds): Spinal Deformity Study Group Radiographic Measurement Manual. Memphis: Medtronic Sofamor Danek, 2005

33. O'Lynnger TM, Zuckerman SL, Morone PJ, Dewan MC, Vasquez-Castellanos RA, Cheng JS: Trends for spine surgery for the elderly: implications for access to healthcare in North America. Neurosurgery 77 (Suppl 4):S136-S141, 2015

34. Pellisé F, Vila-Casademunt A, Ferrer M, Domingo-Sàbat M, Bagó J, Pérez-Grueso FJ, et al: Impact on health related quality of life of adult spinal deformity (ASD) compared with other chronic conditions. Eur Spine J 24:3-11, 2015

35. Pérennou D, Marcelli C, Hérisson C, Simon L: Adult lumbar scoliosis. Epidemiologic aspects in a low-back pain population. Spine (Phila Pa 1976) 19:123-128, 1994

36. Peters A, Verma K, Slobodyanyuk K, Cheriyan T, Hoelscher C, Schwab F, et al: Antifibrinolytics reduce blood loss in adult spinal deformity surgery: a prospective, randomized controlled trial. Spine (Phila Pa 1976) 40:E443-E449, 2015

37. Rillardon L, Levassor N, Guigui P, Wodecki P, Cardinne L, Templier A, et al: [Validation of a tool to measure pelvic and spinal parameters of sagittal balance.] Rev Chir Orthop Repar Appar Mot 89:218-227, 2003 (Fr)

38. Robin GC, Span Y, Steinberg R, Makin M, Menczel J: Scoliosis in the elderly: a follow-up study. Spine (Phila Pa 1976) 7:355-359, 1982

39. Sansur CA, Smith JS, Coe JD, Glassman SD, Berven SH, Polly DW Jr, et al: Scoliosis research society morbidity and mortality of adult scoliosis surgery. Spine (Phila Pa 1976) 36:E593-E597, 2011

40. Scheer JK, Mundis GM, Klineberg E, Hart RA, Deviren V, Nguyen S, et al: Postoperative recovery after adult spinal de- 
formity surgery: comparative analysis of age in 149 patients during 2-year follow-up. Spine (Phila Pa 1976) 40:15051515,2015

41. Schwab F, Dubey A, Gamez L, El Fegoun AB, Hwang K, Pagala M, et al: Adult scoliosis: prevalence, SF-36, and nutritional parameters in an elderly volunteer population. Spine (Phila Pa 1976) 30:1082-1085, 2005

42. Schwab F, Ungar B, Blondel B, Buchowski J, Coe J, Deinlein D, et al: Scoliosis Research Society-Schwab adult spinal deformity classification: a validation study. Spine (Phila Pa 1976) 37:1077-1082, 2012

43. Schwab FJ, Blondel B, Bess S, Hostin R, Shaffrey CI, Smith JS, et al: Radiographical spinopelvic parameters and disability in the setting of adult spinal deformity: a prospective multicenter analysis. Spine (Phila Pa 1976) 38:E803-E812, 2013

44. Schwab FJ, Hawkinson N, Lafage V, Smith JS, Hart R, Mundis G, et al: Risk factors for major peri-operative complications in adult spinal deformity surgery: a multi-center review of 953 consecutive patients. Eur Spine J 21:2603-2610, 2012

45. Sciubba DM, Yurter A, Smith JS, Kelly MP, Scheer JK, Lafage $\mathrm{V}$, et al: A comprehensive review of complication rates following surgery for adult deformity: a reference for informed consent. Spine Deform 3:575-594, 2015

46. Shaffrey E, Smith JS, Lenke LG, Polly DW Jr, Chen CJ, Coe JD, et al: Defining rates and causes of mortality associated with spine surgery: comparison of 2 data collection approaches through the Scoliosis Research Society. Spine (Phila Pa 1976) 39:579-586, 2014

47. Smith JS, Fu KM, Urban P, Shaffrey CI: Neurological symptoms and deficits in adults with scoliosis who present to a surgical clinic: incidence and association with the choice of operative versus nonoperative management. J Neurosurg Spine 9:326-331, 2008

48. Smith JS, Klineberg E, Schwab F, Shaffrey CI, Moal B, Ames CP, et al: Change in classification grade by the SRSSchwab Adult Spinal Deformity Classification predicts impact on health-related quality of life measures: prospective analysis of operative and nonoperative treatment. Spine (Phila Pa 1976) 38:1663-1671, 2013

49. Smith JS, Lafage V, Shaffrey C, Schwab F, Lafage R, Hostin $\mathrm{R}$, et al: Outcomes of operative and nonoperative treatment for adult spinal deformity: a prospective, multi-center propensity-matched cohort assessment with minimum two-year follow-up. Neurosurgery [epub ahead of print], 2015

50. Smith JS, Sansur CA, Donaldson WF III, Perra JH, Mudiyam R, Choma TJ, et al: Short-term morbidity and mortality associated with correction of thoracolumbar fixed sagittal plane deformity: a report from the Scoliosis Research Society Morbidity and Mortality Committee. Spine (Phila Pa 1976) 36:958-964, 2011

51. Smith JS, Saulle D, Chen CJ, Lenke LG, Polly DW Jr, Kasliwal MK, et al: Rates and causes of mortality associated with spine surgery based on 108,419 procedures: a review of the Scoliosis Research Society Morbidity and Mortality Database. Spine (Phila Pa 1976) 37:1975-1982, 2012

52. Smith JS, Shaffrey CI, Ames CP, Demakakos J, Fu KM, Keshavarzi S, et al: Assessment of symptomatic rod fracture after posterior instrumented fusion for adult spinal deformity. Neurosurgery 71:862-867, 2012

53. Smith JS, Shaffrey CI, Berven S, Glassman S, Hamill C, Horton W, et al: Improvement of back pain with operative and nonoperative treatment in adults with scoliosis. Neurosurgery 65:86-94, 2009

54. Smith JS, Shaffrey CI, Berven S, Glassman S, Hamill C, Horton W, et al: Operative versus nonoperative treatment of leg pain in adults with scoliosis: a retrospective review of a prospective multicenter database with two-year follow-up. Spine (Phila Pa 1976) 34:1693-1698, 2009
55. Smith JS, Shaffrey CI, Glassman SD, Berven SH, Schwab FJ, Hamill CL, et al: Risk-benefit assessment of surgery for adult scoliosis: an analysis based on patient age. Spine (Phila Pa 1976) 36:817-824, 2011

56. Smith JS, Shaffrey CI, Glassman SD, Carreon LY, Schwab FJ, Lafage V, et al: Clinical and radiographic parameters that distinguish between the best and worst outcomes of scoliosis surgery for adults. Eur Spine J 22:402-410, 2013

57. Smith JS, Shaffrey CI, Lafage V, Schwab F, Scheer JK, Protopsaltis T, et al: Comparison of best versus worst clinical outcomes for adult spinal deformity surgery: a retrospective review of a prospectively collected, multicenter database with 2-year follow-up. J Neurosurg Spine 23:349-359, 2015

58. Smith JS, Shaffrey CI, Sansur CA, Berven SH, Fu KM, Broadstone PA, et al: Rates of infection after spine surgery based on 108,419 procedures: a report from the Scoliosis Research Society Morbidity and Mortality Committee. Spine (Phila Pa 1976) 36:556-563, 2011

59. Smith JS, Shaffrey E, Klineberg E, Shaffrey CI, Lafage V, Schwab FJ, et al: Prospective multicenter assessment of risk factors for rod fracture following surgery for adult spinal deformity. J Neurosurg Spine 21:994-1003, 2014

60. Smith JS, Singh M, Klineberg E, Shaffrey CI, Lafage V, Schwab FJ, et al: Surgical treatment of pathological loss of lumbar lordosis (flatback) in patients with normal sagittal vertical axis achieves similar clinical improvement as surgical treatment of elevated sagittal vertical axis: clinical article. J Neurosurg Spine 21:160-170, 2014

61. Smith MW, Annis P, Lawrence BD, Daubs MD, Brodke DS: Acute proximal junctional failure in patients with preoperative sagittal imbalance. Spine J 15:2142-2148, 2015

62. Tang JA, Leasure JM, Smith JS, Buckley JM, Kondrashov D, Ames CP: Effect of severity of rod contour on posterior rod failure in the setting of lumbar pedicle subtraction osteotomy (PSO): a biomechanical study. Neurosurgery 72:276-283, 2013

63. Theologis AA, Burch S: Prevention of acute proximal junctional fractures after long thoracolumbar posterior fusions for adult spinal deformity using 2-level cement augmentation at the upper instrumented vertebra and the vertebra 1 level proximal to the upper instrumented vertebra. Spine (Phila Pa 1976) 40:1516-1526, 2015

64. Theologis AA, Demirkiran G, Callahan M, Pekmezci M, Ames C, Deviren V: Local intrawound vancomycin powder decreases the risk of surgical site infections in complex adult deformity reconstruction: a cost analysis. Spine (Phila Pa 1976) 39:1875-1880, 2014

65. Verma K, Errico T, Diefenbach C, Hoelscher C, Peters A, Dryer J, et al: The relative efficacy of antifibrinolytics in adolescent idiopathic scoliosis: a prospective randomized trial. J Bone Joint Surg Am 96:e80, 2014

66. Worley N, Marascalchi B, Jalai CM, Yang S, Diebo B, Vira $\mathrm{S}$, et al: Predictors of inpatient morbidity and mortality in adult spinal deformity surgery. Eur Spine $\mathbf{J}$ [epub ahead of print], 2015

67. Zhu F, Bao H, Liu Z, Bentley M, Zhu Z, Ding Y, et al: Unanticipated revision surgery in adult spinal deformity: an experience with 815 cases at one institution. Spine (Phila Pa 1976) 39:B36-B44, 2014

\section{Disclosures}

The International Spine Study Group (ISSG) is funded through research grants from DePuy Synthes and individual donations. Dr. Smith reports being a consultant for Biomet, NuVasive, Medtronic, and Cerapedics; receiving research support from DePuy; receiving non-study-related support from DePuy for clinical or research work overseen by him; and honoraria for teaching from Biomet, NuVasive, Globus, K2M, and DePuy. 
Dr. Klineberg reports being a consultant for DePuy Synthes and Stryker, and receiving honoraria from K2M and AOSpine, and a fellowship grant from AOSpine. Dr. Lafage reports owning stock in Nemaris, receiving non-study-related support from SRS, NIH, and DePuy Synthes Spine for clinical or research work overseen by her; and honoraria for teaching or speaking from Medicrea, DePuy, MSD, and Nemaris. Dr. Shaffrey reports being a consultant for Biomet, Medtronic, and NuVasive; owning stock in NuVasive; and having an ownership interest in and patents and royalties related to Biomet, NuVasive, and Medtronic. Dr. Schwab reports being a consultant for K2M, NuVasive, Medicrea, MSD, and Biomet Zimmer; receiving non-studyrelated support from AO, SRS, and DePuy for clinical or research work overseen by him; owning stock in Nemaris; holding patents related to MSD and $\mathrm{K} 2 \mathrm{M}$; and receiving honoraria for teaching or speaking from K2M, NuVasive, Medicrea, MSD, and Biomet Zimmer. Dr. Hostin reports being a consultant for DePuy Spine, and receiving non-study-related support from NuVasive, Seeger, DJO, DePuy Spine, and K2M for clinical or research work overseen by him. Dr. Mundis reports being a consultant for NuVasive, K2M, Misonix, Medicrea, and Ellipse; and receiving royalties from K2M and NuVasive. Dr. Kim reports being a consultant for $\mathrm{K} 2 \mathrm{M}$ and Biomet, and receiving compensation for being on the speakers' bureaus of DePuy and Stryker. Dr. Protopsaltis reports being a consultant for Medicrea International and for receiving non-study-related support from Zimmer Spine and the Cervical Spine Research Society for clinical or research work overseen by him. Mr. Line reports being a consultant for ISSG. Dr. Gupta reports being a consultant for DePuy, Medtronic, and Orthofix; and owing stock in DePuy, Johnson \& Johnson, Pfizer, Pioneer, and Proctor \& Gamble. Dr. Deviren reports being a consultant for NuVasive, Guidepoint, and Stryker. Dr. Hart reports being a consultant for DePuy Synthes, Globus, and Medtronic; holding a patent related to OHSU; receiving royalties and honoraria for board memberships and speaking engagements from Seaspine, DePuy Synthes, and CSRS; owning stock in Spine Connect and DePuy Synthes; and having an ownership interest in ISSLS and ISSG. Dr. Burton reports being a consultant for, holding a patent related to, and receiving clinical or research support from DePuy. Dr. Bess reports being a consultant for NuVasive and K2M; holding patents related to Innovasis and $\mathrm{K} 2 \mathrm{M}$; receiving clinical or research support from DePuy Spine; receiving non-studyrelated support from Stryker Spine, Medtronic, K2M, Biomet, and Innovasis for clinical or research work overseen by him. Dr. Ames reports being employed by the University of California, San Francisco; being a consultant for DePuy, Medtronic, and Stryker; owning stock in Doctors Research Group; holding a patent related to Fish \& Richardson; and receiving royalties from Biomet Spine and Stryker.

\section{Author Contributions}

Conception and design: Smith, Klineberg, V Lafage, Bess, Ames. Acquisition of data: Smith, Klineberg, V Lafage, Shaffrey, Schwab, Hostin, Mundis, Errico, Kim, Protopsaltis, Hamilton, Scheer, Soroceanu, Kelly, Gupta, Deviren, Hart, Burton, Bess, Ames. Analysis and interpretation of data: Smith, Klineberg, V Lafage, R Lafage, Scheer, Line. Drafting the article: Smith. Critically revising the article: all authors. Reviewed submitted version of manuscript: all authors. Approved the final version of the manuscript on behalf of all authors: Smith. Statistical analysis: Smith. Administrative/technical/material support: V Lafage, Bess. Study supervision: Klineberg, Shaffrey, Bess, Ames.

\section{Correspondence}

Justin S. Smith, Department of Neurosurgery, University of Virginia Health System, Box 800212, Charlottesville, VA 22908. email: jss7f@virginia.edu. 